\title{
Modularized laparoscopic regional en bloc mesogastrium excision (rEME) based on membrane anatomy for distal gastric cancer
}

\author{
Jian Shen ${ }^{1} \cdot$ Xiaogang Dong ${ }^{1} \cdot$ Zhu Liu ${ }^{1} \cdot$ Guoguang Wang ${ }^{1} \cdot$ Jing Yang ${ }^{1} \cdot$ Fei Zhou ${ }^{1} \cdot$ Ming Lu $^{1} \cdot$ Xiang Ma $^{1} \cdot$ Yuan $\mathrm{Li}^{2}$. \\ Chaoyang Tang ${ }^{1} \cdot$ Xiagang Luo $^{1} \cdot$ Qinghong Zhao ${ }^{1}$. Jianping Zhang ${ }^{1}$
}

Received: 19 April 2018 / Accepted: 20 July 2018 / Published online: 27 July 2018

(c) The Author(s) 2018

\begin{abstract}
Background The purpose of the study was to evaluate the safety and feasibility of a new surgical procedure named modularized laparoscopic regional En bloc mesogastrium excision (rEME) based on the membrane anatomy in distal laparoscopic radical gastrectomy for gastric cancer.

Methods From January 2014 to June 2017, 92 consecutive cases of patients with stages I-III distal gastric cancer were divided into 2 groups: laparoscopic radical gastrectomy plus standard $\mathrm{D}_{2}$ lymph node dissection (SD group, $n=44$ ) and modularized rEME (rEME group, $n=48$ ). Evaluations were made in terms of the operative data, pathological results, recovery time of digestive tract functions, complications, and length of stay.

Results 85 patients (SD group, $n=40$ and rEME group, $n=45$ ) were finally included for analysis. There were no significant differences in the median total numbers of dissected LNs ( $31.98 \pm 10.48$ vs. $34.93 \pm 13.12, p=0.261)$, LNs in the greater curvature $(12.18 \pm 6.55$ vs. $13.62 \pm 8.09, p=0.444)$, LNs in the lesser curvature $(19.55 \pm 7.40$ vs. $17.98 \pm 8.31, p=0.365)$ between the SD and rEME groups. The rEME group showed lower loss of blood volume $(107.11 \pm 60.13 \mathrm{ml}$ vs. $146.25 \pm 85.78 \mathrm{ml}$, $p=0.019$ ). No significant differences were found in recovery time of digestive tract functions, postoperative complication rates and length of hospital stay between the two groups.

Conclusion Laparoscopic radical gastrectomy plus modularized rEME based on the membrane anatomy is a safe and feasible procedure for distal gastric cancer.
\end{abstract}

Keywords Gastric cancer $\cdot \mathrm{rEME} \cdot$ Membrane anatomy $\cdot \mathrm{D}_{2} \mathrm{LN}$ dissection $\cdot$ Surgical technique

Gastric cancer is one of the most common malignant tumors and the third leading cause of cancer-related mortality worldwide [1]. In general, incidence rates are highest in East Asia, including China [2]. In most countries, more than $80 \%$ of patients with gastric cancer are diagnosed with advanced gastric cancer (AGC). R0 resection combined with $\mathrm{D}_{2} \mathrm{LN}$ dissection is recognized as the golden standard of surgical

Jian Shen, Xiaogang Dong and Zhu Liu have contributed equally as first authors.

Jianping Zhang

drzhang_jp@126.com

1 Department of General Surgery, The Second Affiliated Hospital, Nanjing Medical University, Jiangjiayuan No. 121, Nanjing 210011, Jiangsu, China

2 The Jiangsu Key Lab of Cancer Biomarkers, Prevention and Treatment, Nanjing Medical University, Nanjing 211166, Jiangsu, China treatment for AGC especially in Asian countries [3]. In the past decade, laparoscopic surgery has become more widely accepted as a surgical treatment for gastric cancer (GC) because of its advantages in minimal invasiveness and also it has been increasingly applied in AGC [4-7]; however, laparoscopic $\mathrm{D}_{2} \mathrm{LN}$ dissection is still technically difficult and its applicability is limited at present.

In the recent two decades, the total mesorectal excision (TME) [8] and complete mesocolic excision (CME) [9] with central vascular ligation (CVL) based on the embryology and anatomy has been recommended as the standard surgery for rectal and colon cancer, with excellent local control of the disease and improved survival rates. Different from TME and CME, en bloc mesogastrium excision (EME) seems impossible to perform attributable to the deficiency of a unified Toldt's-like separating space nor can single vessel be ligated at the root. On the consideration of embryology and membrane anatomy, the pancreas is an exceptional organ 
which interrupted the extension of Toldt's space to the upper abdomen, and all the inherent vessels of stomach origin from coeliac trunk are located in its surface. If we consider the pancreas as a landmark, the stomach's mesentery can be divided into several relatively independent regions. In each region, total mesogastrium including LNs and vessels (right gastroepiploic artery RGEA, left gastroepiploic artery LGEA, right gastric artery RGA and left gastric artery LGA, respectively) can be resected en bloc.

Consequently, we present a modularized laparoscopic surgical procedure of rEME for distal gastric cancer and evaluate its safety and feasibility.

\section{Materials and methods}

\section{Patients}

We retrospective analyzed 92 consecutive patients who were performed laparoscopic radical distal gastrectomy in the Second Affiliated Hospital of Nanjing Medical University between January 2014 and June 2017. On the basis of previous studies [4-6], the inclusion criteria were as follows: age between 20 and 85 years old with pathological diagnosis of gastric cancer; $T_{1}, T_{2-3}$, or $T_{4 \mathrm{a}}$ lesions and metastasis stage $M_{0}$ pre-operation; a performance status of 0-2 according to the Eastern Cooperative Oncology Group (ECOG) [10]. Exclusion criteria: pathological $T_{4 \mathrm{~b}}$ tumors post-operation; previous treatment for cancer; previous upper abdominal surgery; emergency surgery (bleeding, obstruction, or perforation caused by gastric cancer). This study was reviewed and approved by the Ethics Committee of the Second Affiliated Hospital of Nanjing Medical University.

\section{Surgical technique}

All patients were given general anesthesia and placed in the reverse Trendelenburg position with head elevated about $15^{\circ}-20^{\circ}$. The surgeon stands on the patient's left side, the assistant for camera stand between the patient's legs, and another assistant is on the right side. The sequence of rEME was modularized as "infra-pyloric to supra-pyloric to suprapancreatic to spleen hilar region" during the distal laparoscopic radical gastrectomy.

\section{Infra-pyloric region}

Approach and separation space Firstly, the transverse mesocolon was detached from the mesogastrium $(\mathrm{Mg})$ to follow the "line" of "inferior margin of pancreas." Secondly, the pancreatic envelope was expected to open at the point of the pancreatic neck (projection of superior mesenteric vein, SMV) to the anterior pancreas space, and the separation continued following this space rightward (Fig. 1A, C). Ligation of inherent vessels The vessels, middle colonic vein (MCV), Henle's trunk, accessory right colic vein (ARCV), right gastroepiploic vein (RGEV), right gastroepiploic artery (RGEA), and infra-pyloric artery IPA which distributed in this space were visible in sequence. The RGEV is commonly at the anterior of RGEA, and these two vessels together with the surface of pancreas constitute a triangle (we call it "right gastroepiploic golden triangle") which was the landmark for
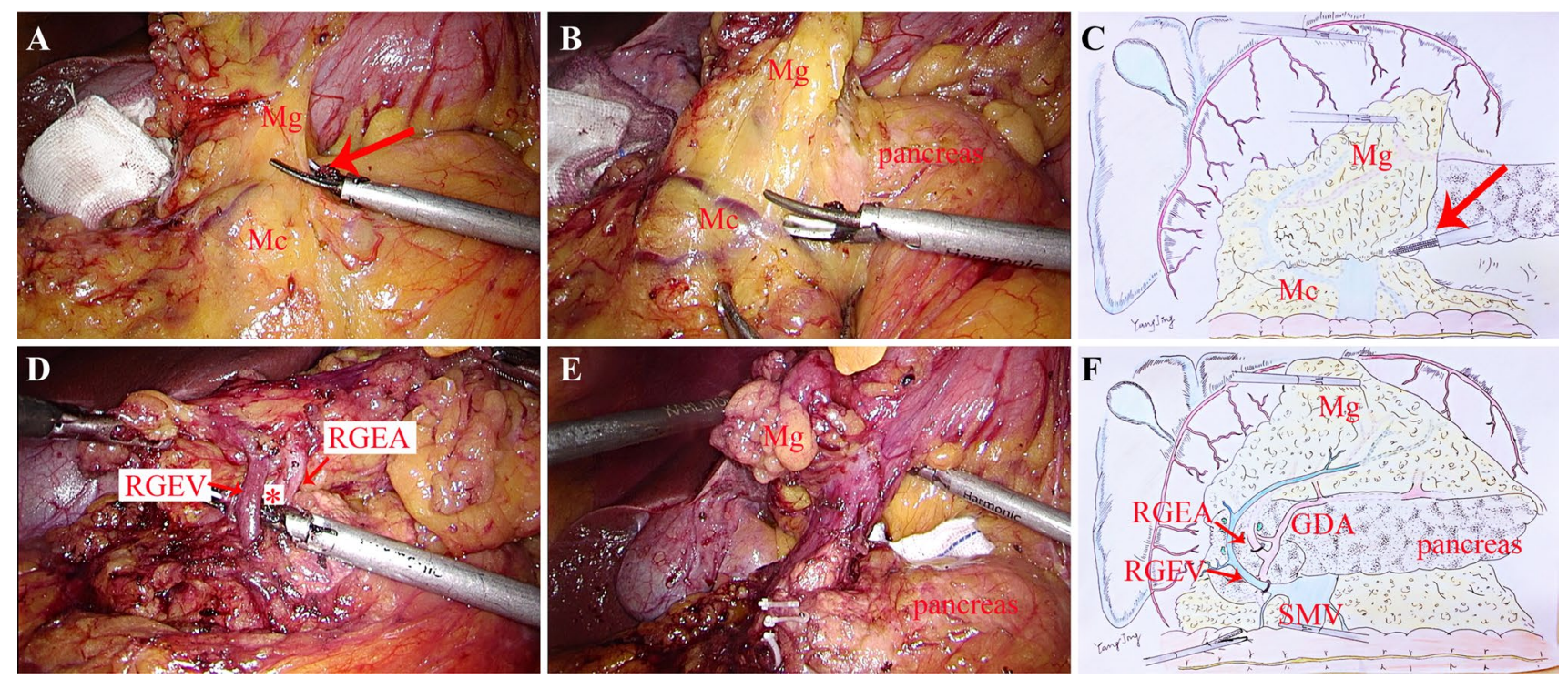

Fig. 1 A Open the fusion gap of $\mathrm{Mg}$ and $\mathrm{Mc}$ (arrow). B The resection of $\mathrm{Mg}$ was begun under the pancreatic envelope. $\mathbf{C}$ The diagram of approach and separation space. D The RGEA and RGEV constitute a triangle together with the surface of pancreas (*). E The regional mesentery of duodenum and stomach were resected en bloc. $\mathbf{F}$ The diagram of rEME in the infra-pyloric region. (Color figure online) 
ligating the vessels (Fig. 1B, D). By tracing the anterior pancreatic space, the lymphatic and adipose tissues were entirely dissociated from the duodenum (Fig. 1E). Regional $E M E$ When this procedure was correctly performed, the regional mesentery including No. 6 LNs was resected en bloc (Fig. 1F).

\section{Supra-pyloric region}

Approach and separation space The separation of anterior pancreatic space continues following the gastroduodenal artery (GDA) (Fig. 2A). Ligation of inherent vessels The accessory mesentery of the RGA was released from the GDA and common hepatic artery (CHA), then the RGA was ligated at the root. The total supra-pyloric mesentery was dissected tracing the surface of proper hepatic artery (PHA) upward to the hepatic hilum with the common bile duct as right boundary and portal vein as left border (Fig. 2B, C). Regional EME The regional mesentery including No. 5, No. 12a, No. 12p and partial No. 8a LNs was then detached from the GDA and PHA and en bloc resected (Fig. 2D).

\section{Supra-pancreatic region}

Approach and separation space The assistant holds the gastro-pancreatic plica with one endoscopic forceps and lift the pancreatic envelope with the other one. The surgeon started along the superior border of the pancreas to open the pancreatic envelope at the join of LGA and splenic artery (Fig. 3A, C), and then the dissection continued rearward to expose the posterior pancreas space with the landmark of Gerota's fascia (Gf) (Fig. 3B). The Gerota's fascia is embryologically the extension of Toldt's space, and here exists a loose connective space lack of vessels between the mesogastrium and the Gerota's fascia. Ligation of inherent vessels The dissection proceeds oriented by the Gerota's fascia leftward till the root of the posterior gastric vessel (preserved) or the middle of splenic artery, and rightward until the left gastric vein(LGV), LGA were visible and ligated at the root in turn (Fig. 3D, E). The separation was continued rightward following the surface of CHA and finally achieved the dissection plane of supra-pyloric region subsequently. Regional EME By this step, the gastric mesentery in the supra-pancreatic region including No. 7, No. 8a, No. 9, and No. $11 \mathrm{p}$ LNs were en bloc excised. The dissection continued upward and leftward tracing the Gerota's fascia till the wall of lower esophagus, and then the duodenum was cut off and the stump of stomach together with the mesentery of the lesser curvature were resected en bloc (Fig. 3F).
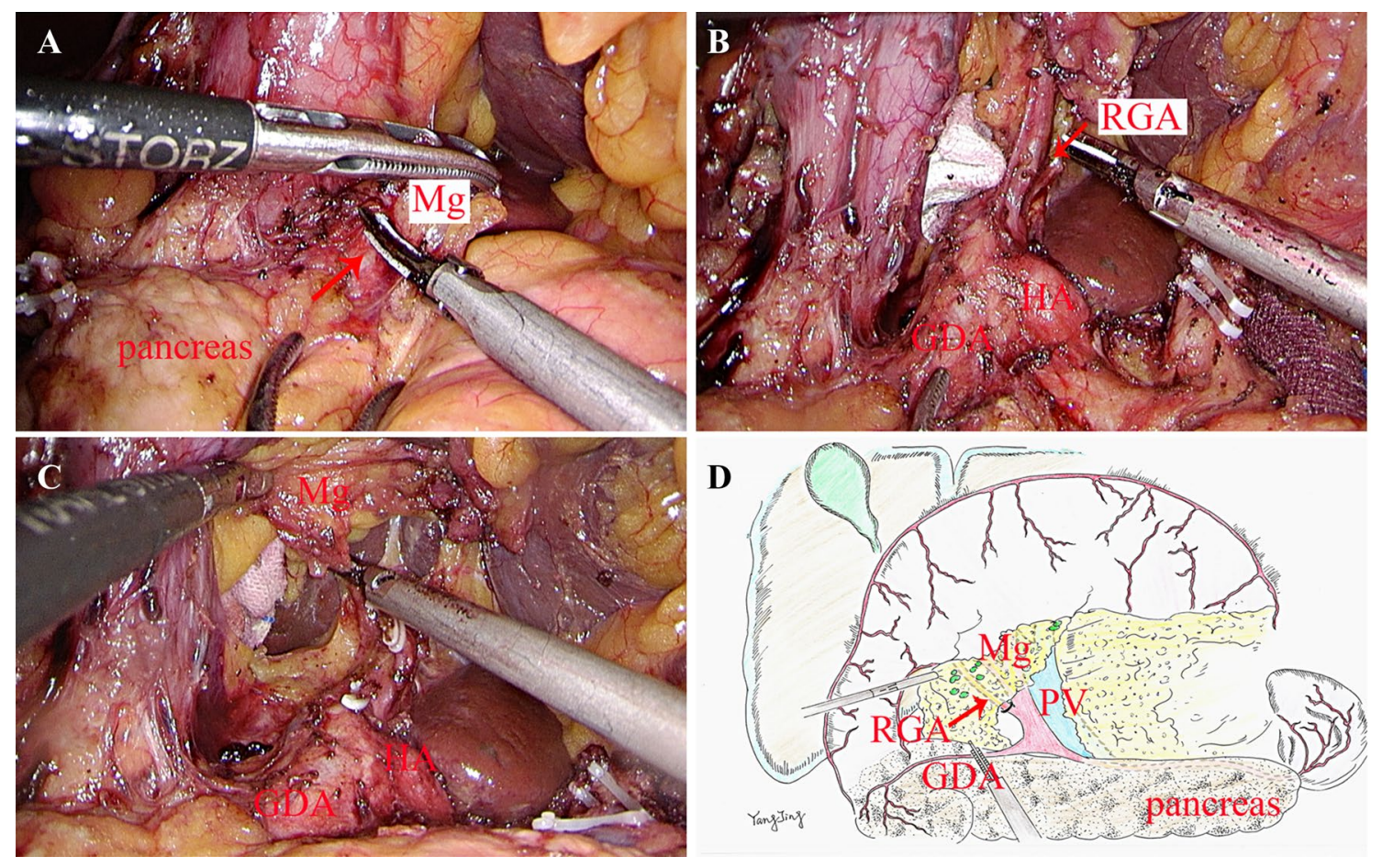

Fig. 2 A The dissection of $\mathrm{Mg}$ was continued tracing the anterior pancreatic space (arrow) at the surface of GDA and CHA. B The total supra-pyloric mesentery was dissected tracing the surface of

PHA upward to the hepatic hilum. C The RGA was released from the GDA and CHA and ligated at the root. D The diagram of rEME in the infra-pyloric region. (Color figure online) 

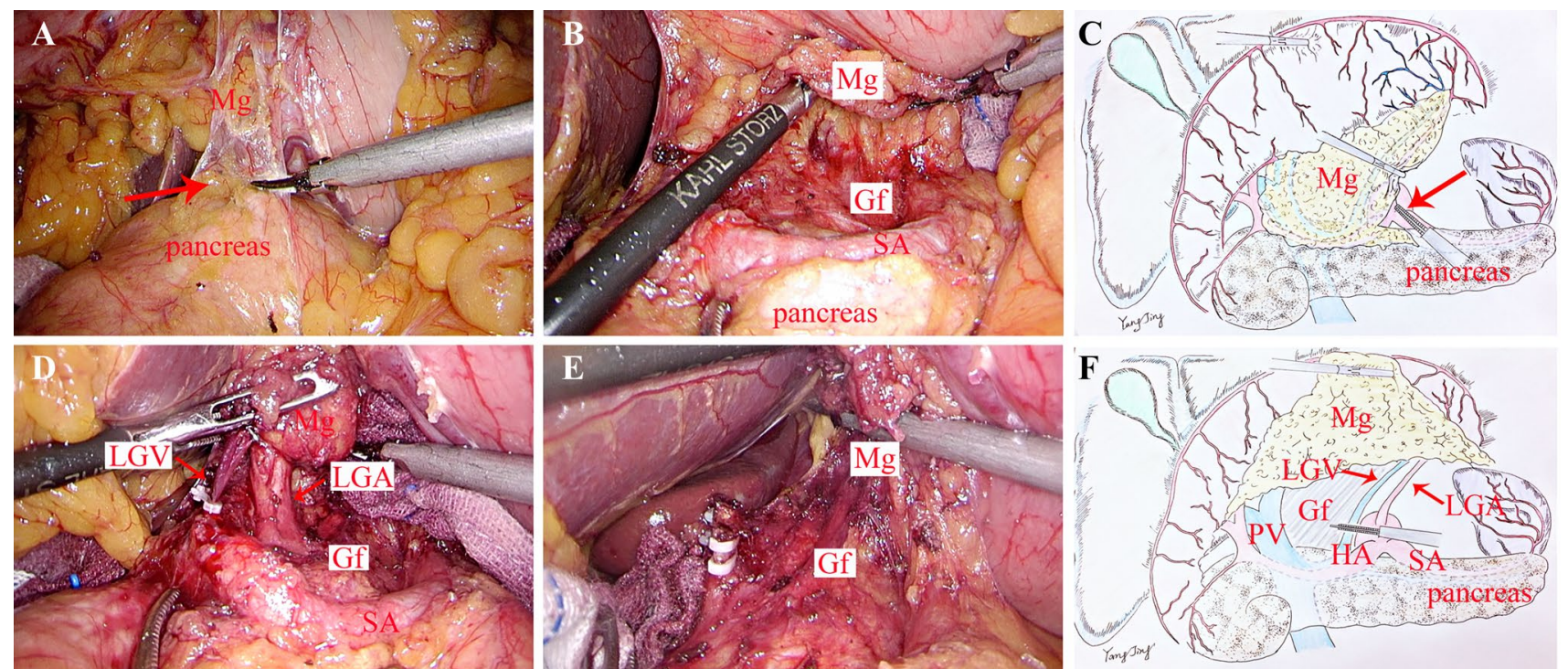

Fig. 3 A The dissection began tracing the anterior pancreas space (arrow). B Dissect rearward following the surface of SA and expose the Gf. C The diagram of approach and separation space. D Dissec-

\section{Spleen hilar region}

Approach and separation space The assistant drafted the stomach rightward and the surgeon pulled the transverse colon oppositely to reveal the fusion plane of mesogastrium tion oriented by the Gf, and LGA and LGV were visible. E The LGA and LGV were both ligated at the root. F The diagram of rEME in the supra-pancreatic region. (Color figure online)

and mesocolon (Mc) (Fig. 4A, C). Then the pancreatic envelope was opened to expose the anterior pancreas space at the inferior border of the pancreas (Fig. 4B). Ligation of inherent vessels The end of the splenic vessels and LGEA were visible in turn by dissection tracing this plane. The
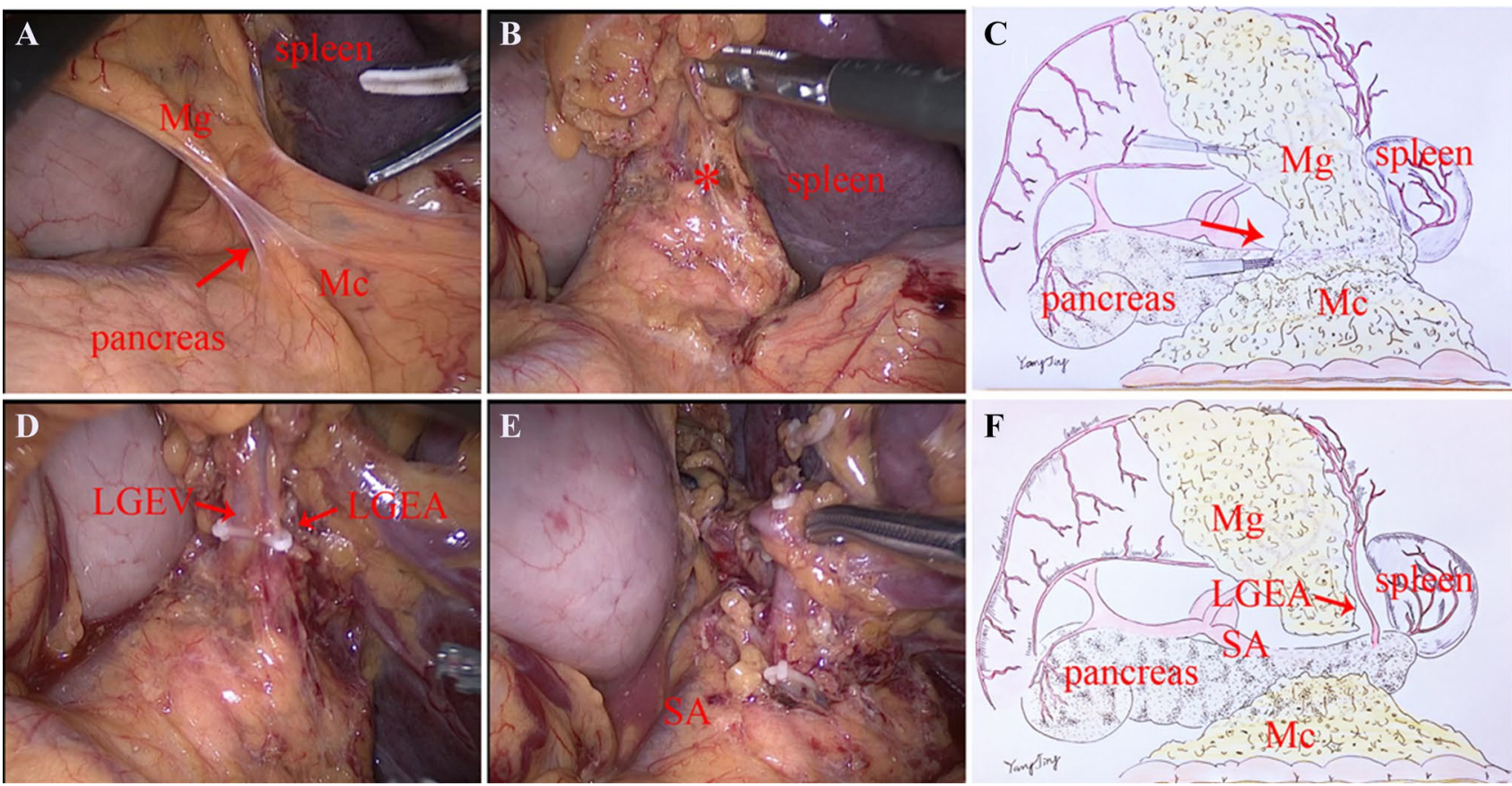

Fig. 4 A The dissection began from the fusion plane of $\mathrm{Mg}$ and $\mathrm{Mc}$ (arrow). B Open the anterior pancreas space (*). C The diagram of approach and separation space. D The LGEV and LGEA were visible in turn and ligated at the root. $\mathbf{E}$ The separation was then turned to the wall of stomach. $\mathbf{F}$ The diagram of rEME in the supra-pancreatic region. (Color figure online) 
mesentery containing No. 4sb LNs attached to LEGA was then pulled up and resected by ligation of the LEGA at the root (Fig. 4D). The separation was then turned to the wall of stomach. Two to three short gastric vessels with their mesentery including No4a LNs were excised by dividing at their roots (Fig. 4E). Regional EME The regional mesentery including No. 4sb, No. 4sa was then en bloc resected (Fig. 4F).

Finally, the distal gastrectomy and reconstruction of the gastrointestinal tract were performed.

\section{Supplement}

If it is necessary to expand dissection of splenic hilar lymph nodes, the complete mesentery in the splenic hilum containing No. 10 LNs should be en bloc resected following this plane according to the "Huang's three-step maneuver" $[11,12]$.

The modularized rEME mentioned above can be successfully performed while avoiding disruption of mesogastrium and remnants of LNs by following these principles: un-touch of the tumor, correct surgical approach, accurate separating plane based on embryology and membrane anatomy, dissection tracing the plane instead of the vessels and en bloc mesogastrium resection.

\section{Statistical analysis}

Consecutive variables were assessed via Student's $t$ test or $t$ ' test. Categorical variables were assessed via Pearson's Chisquared test or Fisher's exact test. $p$ values of less than 0.05 were considered to indicate statistical significance. The analyses were performed with IBM SPSS Statistics 19.0 (SPSS Inc., Chicago, IL, USA).

\section{Results}

A total of 92 consecutive patients with preoperatively pathological diagnosed gastric cancer underwent laparoscopic distal gastrectomy plus radical lymphadenectomy at the Second Affiliated Hospital of Nanjing Medical University between January 2014 and June 2017. Patients were divided into two groups by different surgical procedures: laparoscopic radical gastrectomy plus standard $\mathrm{D}_{2}$ lymph node dissection (SD group, $n=44$ ) and modularized rEME (rEME group, $n=48$ ). Finally, 40 patients ( 25 males, 15 females; mean age, $63.25 \pm 10.62$ years) in SD group and 45 patients ( 29 males, 16 females; mean age, $62.02 \pm 12.35$ years) in rEME group were analyzed after excluded $7 T_{4 \mathrm{~b}}$ patients.

We evaluated the operative date, complications, pathological results, recovery time of digestive tract functions, and length of hospital stay. Patient characteristics and operative outcomes are shown in Table 1. There was no significant difference in the mean longest diameter $(3.14 \pm 2.31 \mathrm{vs}$. $3.34 \pm 1.87 \mathrm{~cm}, p=0.666), T_{1} / T_{2} / T_{3} / T_{4 \mathrm{a}}$ tumors $(12 / 8 / 3 / 17$ vs. $16 / 7 / 3 / 19, p=0.981), \mathrm{LN}$ metastasis rate $(18 / 40$ vs. $18 / 45, p=0.631)$, patients with stage I, II, and III cancer $(19 / 5 / 16$ vs. $19 / 14 / 12, p=0.110)$ between the SD group and rEME group according to the AJCC staging system. The average numbers of total harvested LNs $(31.98 \pm 10.48$ vs. $34.93 \pm 13.12, p=0.261)$, $\mathrm{LNs}$ in the greater curvature $(12.18 \pm 6.55$ vs. $13.62 \pm 8.09, p=0.444)$ and lesser curvature $(19.55 \pm 7.40$ vs. $17.98 \pm 8.31, p=0.365)$ in SD group were similar to those in rEME group (Table 1). The rEME procedure required similar operative times $(253.11 \pm 55.52$ vs. $265.63 \pm 61.39 \mathrm{~min}, p=0.333)$, but showed less blood loss during operation $(107.11 \pm 60.13$ vs. $146.25 \pm 85.78 \mathrm{ml}$, $p=0.019$ ). One patient in each group was conversed to open surgery because of bleeding. All patients began to intake liquid the second day post-operation. The mean time of first flatus ( $3.35 \pm 0.70$ vs. $3.13 \pm 0.98$ days, $p=0.244)$, get out of bed post-operation $(3.80 \pm 2.14$ vs. $4.35 \pm 1.80$ days, $p=0.200)$ and hospital stay $(12.45 \pm 6.53$ vs. $11.44 \pm 3.53$ days, $p=0.374$ ) in SD group were close to the rEME group. No incidence of hospital death was observed in the two groups. The overall incidence of postoperative complications was $20.0 \%$ in the SD group and $15.55 \%$ in the rEME group, with no statistically significant difference $(p=0.592)$ (Table 1).

\section{Discussion}

Gastric cancer is a common digestive tract malignant tumor with high incidence and mortality. Though the neoadjuvant chemoradiotherapy pre-operation accounts for increasing important role in the latest guidelines for the treatment of AGC in the West (including European Society of Medical Oncology, ESMO [13] and National Comprehensive Cancer Network, NCCN [14]). It is undeniable that the treatment of gastric cancer mainly relies on surgery both in the West and the East. Different from the West, $\mathrm{D}_{2} \mathrm{LN}$ dissection plays a very important role or even as the golden standard of surgical treatment for AGC in the Asian countries including China [15]. Although every guideline for gastric cancer treatment emphasizes the importance of LNs dissection, but there is no standardized description for the details of the definition of LNs grouping and technicality for dissection. Most of the guidelines only require the harvested LN numbers over 15. The Japanese Gastric Cancer Treatment Guideline relatively characterizes the LNs grouping, but it is still impossible to standardize the details of the procedure [3]. In particular, LNs dissection during laparoscopic radical resection for gastric cancer is technically difficult along the blood vessels because of the various anatomic variations 
Table 1 Patient characteristics and surgical outcomes

\begin{tabular}{|c|c|c|c|}
\hline Variable & SD group & rEME group & $p$ value \\
\hline Number & 40 & 45 & \\
\hline Age $($ mean $\pm S D)$ & $63.25 \pm 10.62$ & $62.02 \pm 12.35$ & 0.629 \\
\hline Gender (male/female) & $(25 / 15)$ & $(29 / 16)$ & 0.046 \\
\hline Longest diameter $($ mean $\pm \mathrm{SD})$ & $3.14 \pm 2.31 \mathrm{~cm}$ & $3.34 \pm 1.87 \mathrm{~cm}$ & 0.666 \\
\hline Depth of invasion $\left(T_{1} / T_{2} / T_{3} / T_{4 \mathrm{a}}\right)$ & $(12 / 8 / 3 / 17)$ & $(16 / 7 / 3 / 19)$ & 0.981 \\
\hline Lymph node metastasis $\left(N_{0} / N_{1} / N_{2} / N_{3}\right)$ & $(22 / 3 / 6 / 9)$ & $(27 / 6 / 4 / 8)$ & 0.631 \\
\hline TNM stage (I/II/III) & $(19 / 5 / 16)$ & $(19 / 14 / 12)$ & 0.110 \\
\hline Operation time, $\min ($ mean $\pm S D)$ & $265.63 \pm 61.39$ & $253.11 \pm 55.52$ & 0.333 \\
\hline Blood loss, ml (mean \pm SD) & $146.25 \pm 85.78$ & $107.11 \pm 60.13$ & $0.019 *$ \\
\hline Number of dissected lymph nodes, number $($ mean \pm SD) & $31.98 \pm 10.48$ & $34.93 \pm 13.12$ & 0.261 \\
\hline Number of dissected lymph nodes in the greater curvature, number (mean $\pm S D)$ & $12.18 \pm 6.55$ & $13.62 \pm 8.09$ & 0.444 \\
\hline Number of dissected lymph nodes in the lesser curvature, number (mean $\pm \mathrm{SD}$ ) & $19.55 \pm 7.40$ & $17.98 \pm 8.31$ & 0.365 \\
\hline Postoperative hospital stays, days (mean \pm SD) & $12.45 \pm 6.53$ & $11.44 \pm 3.53$ & 0.374 \\
\hline The time to first flatus, days (mean \pm SD) & $3.35 \pm 0.70$ & $3.13 \pm 0.98$ & 0.244 \\
\hline The first time to get out of bed, days (mean \pm SD) & $3.80 \pm 2.14$ & $4.35 \pm 1.80$ & 0.200 \\
\hline Postoperative complications & $8(20.00 \%)$ & $7(15.55 \%)$ & 0.592 \\
\hline Abdominal infection & $1(2.50 \%)$ & $1(2.22 \%)$ & 1 \\
\hline Pulmonary infection & $3(7.50 \%)$ & $4(8.89 \%)$ & 1 \\
\hline Anastomotic bleeding & $1(2.50 \%)$ & $1(2.22 \%)$ & 1 \\
\hline Anastomotic leakage & $1(2.50 \%)$ & $1(2.22 \%)$ & 1 \\
\hline Duodenal stump leakage & $2(5.0 \%)$ & 0 & 0.219 \\
\hline
\end{tabular}

Repeat cases not included

$* p<0.05$

and the narrow visual field under laparoscopy. These factors attribute to the difference in the LNs dissection gastric cancer operations between different surgeons and hospitals. It will be helpful to improve the overall therapeutic results for gastric cancer if the procedure of LNs dissection can be relatively standardized. The aim of digestive tract cancer surgery is to resect the primary tumor with its accessory mesentery containing the lymphatic drainage system including sharp dissection of the visceral plane from the parietal plane which is the core technique in colorectal surgery of TME and CME. Briefly, intact layers of mesocolon was separated from the parietal plane and a maximum number of harvested LNs via true central ligation of the supplying vessels at their roots during TME or CME. The anatomical basis of this approach is that there exists an innate natural space between the mesocolon covered by an enveloped visceral layer and the retroperitoneal parietal plane which is called Toldt's space $[16,17]$. But it is not directly applicable for en bloc mesogastrium excision (EME) because the stomach has embryologically unique mesenteries compared with the colon. Bursectomy was one of the current surgical approaches while the key technical points of this procedure were to separate the anterior membrane of the transverse colon mesentery and the pancreatic capsule. It is technically difficult to perform bursectomy in laparoscopic surgery as surgeons would be prone to enter the wrong horizontal plane and injure the transverse colon vessels. On the other hand, the bursectomy was not improved the prognosis for patients with $\mathrm{cT}_{3}(\mathrm{SS}) / \mathrm{cT}_{4} \mathrm{a}(\mathrm{SE})$ gastric cancer [18]. However, the principles (un-touch of the tumor, separating plane based on embryology and membrane anatomy, en bloc mesogastrium resection) in bursectomy by open were also crucial to obey in other laparoscopic surgical procedures for gastric cancer.

If we consider the pancreas, liver, and spleen as mesenteric components of the stomach, the Toldt's space can be extended to the upper abdomen. The simplest way is to sharp dissection tracing the retroperitoneum parietal plane and ligated at the root of celiac trunk to completely remove the stomach and its mesentery. On the contrary, celiac trunk must be preserved as it offers arteries not only for stomach but also for other organs like liver, gallbladder, pancreas, and spleen. However, the four inherent arteries (RGEA, LGEA, RGA, and LGA) of the stomach origining from the celiac trunk can be detached and ligated at their roots. Moreover, the regional mesogastrium affiliated to these inherent vessels can be en bloc resected respectively. Accordingly, we divided the mesogastrium into four relatively independent regions to excision: infra-pyloric region, supra-pyloric region, spleen hilar region, and supra-pancreatic central region. There exists the constant fusion space between the mesogastrium and deep 
tissues for separation in their respective regions. These spaces can be considered as the cephalic extension of the Toldt's space across the transverse mesocolon. The Toldt's space was separated into two parts by the pancreas named anterior and posterior pancreas space, which fuse together again at the superior of pancreas and extend to the crura of diaphragm. The rEME can be easily performed tracing the anterior pancreas space between the envelope and pancreatic parenchyma in the infra-pyloric region, supra-pyloric region, and spleen hilar region (Figs. 1, 2, 4). The extending Toldt's space in the supra-pancreatic central region is irregular due to the anatomical peculiarities, but the posterior part of the space named Gerota's fascia is characterized as a smooth plane which can be easily recognized and oriented to complete rEME in this region (Fig. 3). Therefore, the ligation of vessels at the root and rEME can be successfully achieved according to reasonable surgical approach, correct anatomical space and modularized separation procedure in these four regions.

In most of the current studies, all regional LNs dissection is oriented by vessels. The most significant limitation of this approach is that the gastric mesentery will be broken during the sharp dissection of vascular and resulting remnants of mesenteric tissues containing LNs. While the mesogastrium could be resected en bloc by the rEME procedure which can avoid the tumor cell's detachment and residue during operation and may obtain long-term survival benefits. Besides, it is always difficult to find the vessels directly in obese patients $[19,20]$. It is believed that the contiguous mesogastric and fusion fascia can be separated by tracing mesothelial and connective tissue layers which generate the laparoscopic surgical planes for separation. The laparoscopic rEME oriented by mesofascial plane separation which is based on embryological considerations is easy to be modularized and it is helpful to avoid injury vascular and pancreatic parenchyma [21]. In this series, the mean intraoperative blood loss in rEME group was $107.11 \pm 60.13 \mathrm{ml}$ and only one patient conversed to open surgery because of bleeding which was better than the SD group. The length of hospital stay was $11.44 \pm 3.53$ days, which was similar to other studies from Korea and China [22-24]. The mean numbers of LNs harvested in rEME were $34.93 \pm 13.12$ which was more than the SD group $(31.98 \pm 10.48)$ but without statistical difference. This advantage may be revealed by a larger sample size in the future studies. In both groups, the mean numbers of LNs harvested were far exceeded the 15 LNs required by the guidelines $[13,14]$ and the average numbers of LNs in the greater curvature and lesser curvature were $(12.18 \pm 6.55$ vs. $13.62 \pm 8.09, p=0.444)$ and $(19.55 \pm 7.40$ vs. $17.98 \pm 8.31$, $p=0.365)$ in SD and rEME group, respectively. The quality of lymph node dissection can be maintained in comparison with that in previous reports whether from the West or the East [15, 25-27] which suggests that this procedure can provide pathologically reliable lymphadenectomy. By the anatomical sharp dissection tracing the reasonable plane and space, the average blood loss and duration of surgery were also similar to other studies from big centers [22, 25]. Postoperative complications developed in seven patients (15.55\%), including Clavien-Dindo classification of IIIb in two. One of these two patients suffered anastomotic bleeding and leakage. The postoperative morbidity and mortality were similar to the SD group and the results in Chinese population $[15,22,28]$. This procedure was a modularized separation procedure following four principles: reasonable surgical approach, accurate anatomical space, vascular ligation at the root, en bloc mesogastrium resection. As a result, sufficient LNs were consistently retrieved by this procedure. Moreover, surgeons can learn to perform this modular procedure easily and quickly with a shorter learning curve. One limitation of this study is that the oncological outcomes were not mature, and the evaluation of the long-term outcomes is in progress.

\section{Conclusion}

In conclusion, our standardized technique of modularized laparoscopic rEME for distal gastric cancer is safe and technically feasible. In order to determine the long-term clinical outcomes of rEME, longer period of follow-up and extension to multicenter of this procedure is ongoing.

Acknowledgements We are grateful to Professors Guoxin Li (Department of General Surgery, Nanfang Hospital, Southern Medical University, China) and Changming Huang (Department of Gastric Surgery, Fujian Medical University Union Hospital, China) for their technical guidance.

\section{Compliance with ethical standards}

Disclosures Jian Shen, Xiaogang Dong, Zhu Liu, Guoguang Wang, Jing Yang, Fei Zhou, Ming Lu, Xiang Ma, Yuan Li, Chaoyang Tang, Xiagang Luo, Qinghong Zhao, and Jianping Zhang have no conflicts of interest or financial ties to disclose.

Open Access This article is distributed under the terms of the Creative Commons Attribution 4.0 International License (http://creativeco mmons.org/licenses/by/4.0/), which permits unrestricted use, distribution, and reproduction in any medium, provided you give appropriate credit to the original author(s) and the source, provide a link to the Creative Commons license, and indicate if changes were made.

\section{References}

1. Torre LA, Bray F, Siegel RL, Ferlay J, Lortet-Tieulent J, Jemal A (2015) Global cancer statistics, 2012. CA Cancer J Clin 65:87-108

2. Chen W, Zheng R, Baade PD, Zhang S, Zeng H, Bray F, Jemal A, Yu XQ, He J (2016) Cancer statistics in China, 2015. CA Cancer J Clin 66:115-132 
3. Japanese Gastric Cancer Association (2017) Japanese gastric cancer treatment guidelines 2014 (ver. 4). Gastric Cancer 20:1-19

4. Yu J, Hu J, Huang C, Ying M, Peng X, Wei H, Jiang Z, Du X, Liu Z, Liu H, Li G, Chinese Laparoscopic Gastrointestinal Surgery Study (CLASS) Group (2013) The impact of age and comorbidity on postoperative complications in patients with advanced gastric cancer after laparoscopic D2 gastrectomy: results from the Chinese laparoscropic gastrointestinal surgery study (CLASS) group. Eur J Surg Oncol 39:1144-1149

5. Hu Y, Ying M, Huang C, Wei H, Jiang Z, Peng X, Hu J, Du X, Wang B, Lin F, Xu J, Dong G, Mou T, Li G, Chinese Laparoscopic Gastrointestinal Surgery Study (CLASS) Group (2014) Oncologic outcomes of laparoscopy-assisted gastrectomy for advanced gastric cancer: a large-scale multicenter retrospective cohort study from China. Surg Endosc 28:2048-2056

6. Park DJ, Han SU, Hyung WJ, Kim MC, Kim W, Ryu SY, Ryu SW, Song KY, Lee HJ, Cho GS, Kim HH, Korean Laparoscopic Gastrointestinal Surgery Study (KLASS) Group (2012) Long-term outcomes after laparoscopy-assisted gastrectomy for advanced gastric cancer: a largescale multicenter retrospective study. Surg Endosc 26:1548-1553

7. Inaki N, Etoh T, Ohyama T, Uchiyama K, Katada N, Koeda K, Yoshida K, Takagane A, Kojima K, Sakuramoto S, Shiraishi N, Kitano S (2015) A multi-institutional, prospective, phase II feasibility study of laparoscopy-assisted distal gastrectomy with D2 lymph node dissection for locally advanced gastric cancer (JLSSG0901). World J Surg 39:2734-2741

8. Heald RJ, Husband EM, Ryall RD (1982) The mesorectum in rectal cancer surgery - the clue to pelvic recurrence? Br J Surg 69:613-616

9. Hohenberger W, Weber K, Matzel K, Papadopoulos T, Merkel S (2009) Standardized surgery for colonic cancer: complete mesocolic excision and central ligation-technical notes and outcome. Colorectal Dis 11:354-364 discussion 364-5.

10. Oken MM, Creech RH, Tormey DC, Horton J, Davis TE, McFadden ET, Carbone PP. Toxicity and response criteria of the Eastern Cooperative Oncology Group. Am J Clin Oncol. 5:649-55

11. Huang CM, Chen QY, Lin JX, Zheng CH, Li P, Xie JW (2014) Huang's three-step maneuver for laparoscopic spleen-preserving No. 10 lymph node dissection for advanced proximal gastric cancer. Chin J Cancer Res 26:208-210

12. Huang ZN, Huang CM, Zheng CH, Li P, Xie JW, Wang JB, Lin JX, Lu J, Chen QY, Cao LL, Lin M, Tu RH (2016) Learning curve of the application of huang three-step maneuver in a laparoscopic spleen-preserving splenic hilar lymphadenectomy for advanced gastric cancer. Medicine (Baltimore) https://doi.org/10.1097/ MD.0000000000003252

13. Smyth EC, Verheij M, Allum W, Cunningham D, Cervantes A, Arnold D, ESMO Guidelines Committee (2016) Gastric cancer: ESMO Clinical Practice Guidelines for diagnosis, treatment and follow-up. Ann Oncol 27:v38-v49

14. Ajani JA, D’Amico TA, Almhanna K, Bentrem DJ, Chao J, Das P, Denlinger CS, Fanta P, Farjah F, Fuchs CS, Gerdes H, Gibson M, Glasgow RE, Hayman JA, Hochwald S, Hofstetter WL, Ilson DH, Jaroszewski D, Johung KL, Keswani RN, Kleinberg LR, Korn WM, Leong S, Linn C, Lockhart AC, Ly QP, Mulcahy MF, Orringer MB, Perry KA, Poultsides GA, Scott WJ, Strong VE, Washington MK, Weksler B, Willett CG, Wright CD, Zelman D, McMillian N, Sundar H (2016) Gastric cancer, version 3.2016, NCCN Clinical Practice Guidelines in oncology. J Natl Compr Cancer Netw 14:1286-1312

15. Hu Y, Huang C, Sun Y, Su X, Cao H, Hu J, Xue Y, Suo J, Tao K, He X, Wei H, Ying M, Hu W, Du X, Chen P, Liu H, Zheng C, Liu F, Yu J, Li Z, Zhao G, Chen X, Wang K, Li P, Xing J, Li G (2016) Morbidity and mortality of laparoscopic versus open D2 distal gastrectomy for advanced gastric cancer: a randomized controlled trial. J Clin Oncol 34:1350-1357
16. Lirici MM, Hüscher CG (2016) Techniques and technology evolution of rectal cancer surgery: a history of more than a hundred years. Minim Invasive Ther Allied Technol 25:226-233

17. Matsuda T, Sumi Y, Yamashita K, Hasegawa H, Yamamoto M, Matsuda Y, Kanaji S, Oshikiri T, Nakamura T, Suzuki S, Kakeji Y (2017) Anatomical and embryological perspectives in laparoscopic complete mesocoloic excision of splenic flexure cancers. Surg Endosc https://doi.org/10.1007/s00464-017-5792-6

18. Kurokawa Y, Doki Y, Mizusawa J, Terashima M, Katai H, Yoshikawa T, Kimura Y, Takiguchi S, Nishida Y, Fukushima N, Iwasaki Y, Kaji M, Hirao M, Katayama H, Sasako M (2018) Bursectomy versus omentectomy alone for resectable gastric cancer (JCOG1001): a phase 3, open-label, randomised controlled trial. Lancet Gastroenterol Hepatol 3:460-468

19. Cai J, Wei D, Gao CF, Zhang CS, Zhang H, Zhao T (2011) A prospective randomized study comparing open versus laparoscopyassisted D2 radical gastrectomy in advanced gastric cancer. Dig Surg 28:331-337

20. Haverkamp L, Brenkman HJ, Seesing MF, Gisbertz SS, van Berge Henegouwen MI, Luyer MD, Nieuwenhuijzen GA, Wijnhoven BP, van Lanschot JJ, de Steur WO, Hartgrink HH, Stoot JH, Hulsewé KW, Spillenaar Bilgen EJ, Rütter JE, Kouwenhoven EA, van Det MJ, van der Peet DL, Daams F, Draaisma WA, Broeders IA, van Stel HF, Lacle MM, Ruurda JP, van Hillegersberg R, LOGICA study group (2015) Laparoscopic versus open gastrectomy for gastric cancer, a multicenter prospectively randomized controlled trial (LOGICA-trial). BMC Cancer 15:556

21. Hisashi S, Shusuke H, Yu O, Harushi U, Yoshiharu S (2015) Tracing dissectable layers of mesenteries overcomes embryologic Restrictions when performing infrapyloric lymphadenectomy in laparoscopic gastric cancer surgery. J Am Coll Surg https://doi. org/10.1016/j.jamcollsurg.2015.02.037

22. Chen K, Wu D, Pan Y, Cai JQ, Yan JF, Chen DW, Maher H, Mou YP (2016) Totally laparoscopic gastrectomy using intracorporeally stapler or hand-sewn anastomosis for gastric cancer: a singlecenter experience of 478 consecutive cases and outcomes. World J Surg Oncol 14:115

23. Cui M, Li Z, Xing J, Yao Z, Liu M, Chen L, Zhang C, Yang H, Zhang N, Tan F, Jiang B, Di J, Wang Z, Ji J, Su X (2015) A prospective randomized clinical trial comparing $\mathrm{D} 2$ dissection in laparoscopic and open gastrectomy for gastric cancer. Med Oncol 32:241

24. Park YK, Yoon HM, Kim YW, Park JY, Ryu KW, Lee YJ, Jeong O, Yoon KY, Lee JH, Lee SE, Yu W, Jeong SH, Kim T, Kim S, Nam BH, COACT Group (2017) Laparoscopy-assisted versus open D2 distal gastrectomy for advanced gastric cancer: results from a randomized phase II multicenter clinical trial (COACT 1001). Ann Surg https://doi.org/10.1097/SLA.0000000000002168

25. Kim MC, Kim SY, Kim KW (2017) Laparoscopic Reinforcement Suture (LARS) on staple line of duodenal stump using barbed suture in laparoscopic gastrectomy for gastric cancer: a prospective single arm phase II study. J Gastric Cancer 17:354-362

26. Naffouje SA, Salti GI (2017) Extensive lymph node dissection improves survival among american patients with gastric adenocarcinoma treated surgically: analysis of the national cancer database. J Gastric Cancer 17:319-330

27. Shimada S, Sawada N, Ishiyama Y, Nakahara K, Maeda C, Mukai S, Hidaka E, Ishida F, Kudo SE (2018) Impact of obesity on shortand long-term outcomes of laparoscopy assisted distal gastrectomy for gastric cancer. Surg Endosc 32:358-366

28. Li M, Wang XA, Wang L, Wu X, Wu W, Song X, Zhao S, Zhang F, Ma Q, Liang H, Xiang S, Wang Z, Gong W, Dong P, Liu Y (2018) A three-step method for modular lymphadenectomy in gastric cancer surgery: The ability to retrieve sufficient lymph nodes and improve survival. Am J Surg 215:91-96 